\title{
Impact of observers' experience level on counts of fishes in underwater visual surveys
}

\author{
I. D. Williams ${ }^{1,2, *}$, W. J. Walsh ${ }^{2}$, B. N. Tissot ${ }^{3}$, L. E. Hallacher ${ }^{4}$ \\ ${ }^{1}$ Coral Reef Initiative, Research Program, University of Hawaii at Manoa, Social Science Research Institute, \\ 2424 Maile Way, 704, Honolulu, Hawaii 96822, USA \\ ${ }^{2}$ Hawaii Division of Aquatic Resources, Honokohau Marina, 74-380B Kealakehe Parkway, Kailua-Kona, Hawaii 96740, USA \\ ${ }^{3}$ Washington State University Vancouver, 14204 NE Salmon Creek Avenue, Vancouver, Washington 98686, USA \\ ${ }^{4}$ University of Hawaii-Hilo, Department of Biology, Hilo, Hawaii 96720, USA
}

\begin{abstract}
Underwater visual surveys are widely used to estimate reef fish abundance. Using data from repeated surveys of coral reef sites on West Hawai'i, we assessed one possible factor driving variation among and within observers' counts, namely the level of observers' previous survey experience. Increasing experience was associated with higher estimates of species richness and of abundance for some but not all taxa, but no systematic change in intra-observer variability. Least experienced observers counted 66 to $71 \%$ as many Acanthuridae, Labridae, and benthic Pomacentridae as the most experienced observers, and only $44 \%$ as many Holocentridae, those taxa being numerically dominated by small, mobile, or cryptic fishes. In contrast, there was no effect of experience level on counts of more conspicuous or slow-moving taxa: Chaetodontidae, Chromis, and Cirrhitidae. Experience bias is unlikely to be a major problem for survey programs that pool data from multiple observers with broadly similar levels of experience, other than that all sources of difference among observers contribute to increased data variability and consequently lowered statistical power and precision. However, experience bias clearly could be a serious issue for survey or monitoring programs that begin with largely inexperienced survey divers who gain experience and, consequently, tend to count more fish as the program matures. While experience level is not the only factor causing differences among observers, it is relatively easy to recognize and therefore to mitigate.
\end{abstract}

KEY WORDS: Underwater visual survey $\cdot$ Bias $\cdot$ Monitoring $\cdot$ Fish counts Resale or republication not permitted without written consent of the publisher

\section{INTRODUCTION}

Field ecologists and resource managers are constrained by their ability to accurately and precisely survey populations of interest. Underwater visual surveys, which are widely used to estimate reef fish abundance, present a number of specific challenges, including the restriction upon underwater time due to safe diving considerations, and the fact that observer mobility and underwater visibility are generally rather limited compared to the patchy distribution of target organisms (Charton et al. 2000). Therefore, the amount of replication and the spatial scale of sampling units are frequently less than would be desirable, and it is particularly important to recognize and, where possible, reduce the impact of factors contributing to survey error.

Recognized sources of error common to most underwater visual survey techniques include the following: environmental disparities among surveys affecting the detectability of fishes, such as differences in water clarity and habitat characteristics (Thresher \& Gunn 1986); the number and variety of target groups counted simultaneously (Lincoln Smith 1989); observer swimming speed (Lincoln Smith 1988, De Girolamo \& Mazzoldi 2001); survey area dimensions (Sale \& Sharp 1983, Cheal \& Thompson 1997, Kulbicki \& Sarramegna 1999); acquired behavioral characteristics of target fishes (Kulbicki 1998); and the survey methodology utilized (Thresher \& Gunn 1986, Samoilys \& Carlos 
2000). There are also substantial differences among distinct taxonomic or functional groups of fishes; large, conspicuous, non-schooling fishes tend to be easier to count than small, schooling, highly mobile, or cryptic fishes (Lincoln Smith 1989, Samoilys \& Carlos 2000, Stewart \& Beukers 2000).

Where survey programs involve multiple observers, systematic differences among those observers can also contribute to survey error. Inter-observer variability, i.e. consistent differences among observers in the number of fish or species they tend to count, appears to be common (St John et al. 1990, Kulbicki \& Sarramegna 1999), and therefore differences in the make up of survey teams among sites or times could bias results. Differences in intra-observer variability, i.e. among counts by each observer, could also be important. Natural systems are characterized by substantial spatial and temporal variability: if an observer's counts underestimate that variability, their data will not adequately reflect real differences among surveys; if they overestimate that variability, their data will have reduced power and precision. Both can be problematic. Training appears to be an effective way to reduce observer bias, at least for some taxa, but probably has less impact on inherent variability within observers' counts (Thompson \& Mapstone 1997). It seems plausible that experience level might also be a factor affecting inter- or intra-observer variability (Kulbicki \& Sarramegna 1999), but we are not aware of any previous study which has specifically examined this issue.

Using data taken from a long-term, multi-observer monitoring program of 23 coral reef sites located on the west coast of the island of Hawai'i, we examined the extent to which observers' experience level might either bias or affect the precision of the data they generate. Specifically, we assessed the impact of observers' experience on the quality of data they produce, measured in terms of (1) their estimates of species richness and abundance, i.e. number of species and number of fishes counted per survey, and (2) the variability among their counts, variability per observer measured in terms of the coefficient of variation $(\mathrm{COV}=100 \times$ standard deviation/mean $)$ of counts conducted by that observer.

\section{MATERIALS AND METHODS}

Fish monitoring in West Hawai'i. In 1999, the West Hawai'i Aquarium Project (WHAP), a consortium of scientists from the state of Hawai'i's Division of Aquatic Resources (DAR), University of Hawai'i at Hilo (UHH), and Washington State University (WSU) established 23 permanent monitoring sites along the west coast of the island of Hawai'i. Sites were located on mid-depth reefs (10 to $15 \mathrm{~m}$ ) with abundant finger coral Porites compressa, a key habitat for juvenile aquarium fishes, one of the foci of the survey program. Surveys were conducted in 'rounds', each of the 23 sites being surveyed once per round. Rounds took approximately a month to complete, and we generally left a gap of about 1 mo between the end of a round and the start of the next. By May 2004, the last period from which we used data, 32 rounds had been completed.

Details of the survey methodology are given elsewhere (Tissot et al. 2004); in brief, each site survey involved 2 pairs of divers surveying 4 permanent $25 \mathrm{~m}$ transects laid out in 2 parallel rows of 2 transects, with $10 \mathrm{~m}$ gaps between transects in each row and between rows. The 4 transects were always surveyed in the same manner: 1 pair of divers surveying the shallower transects (A and B) and the other pair surveying the deeper transects (C and $D$ ). On each transect, the pair of divers swam in parallel on either side of a transect line, each diver recording all fishes within a $2 \mathrm{~m}$ wide belt on their side of the line. For the first $4 \mathrm{yr}$ of the program, species number and phase (recruit, adult) were recorded for all fishes observed on transects, but since February 2003 fish sizes have been estimated in $5 \mathrm{~cm}$ slots ( 0 to 5,5 to $10 \mathrm{~cm}$, etc.).

Observers' experience levels. Surveys were conducted by a core group of DAR staff, together with a number of UHH and WSU students. In most years, 1 or more of the students left the program, generally when they graduated from UHH, and were replaced by new students. Prior to joining the survey team, all students received a minimum of $2 \mathrm{wk}$ of training in underwater survey methods and species identification through the UH QUEST program-Quantitative Underwater Ecological Survey Techniques (Hallacher \& Tissot 1999) and then completed 2 or 3 training dives in which they followed behind and subsequently compared data with experienced fish counters on actual survey dives. The width of the transect belt was demarcated for new divers by means of a weighted line placed at the start of each transect.

Between February 2003 and May 2004 (being the entire period for which we had survey data including size estimates at the time we initiated this analysis), 24 different observers worked on the survey program. By the end of that period, 3 of those observers, having worked regularly on the program since its inception, had each conducted 300 or more survey dives. Another 4 divers, having been involved for 2 or more years, had conducted 100 or more survey dives each, but there were also 6 observers who had conducted 10 or fewer dives in total (Fig. 1A). This last group conducted only around $5 \%$ of all surveys. Approximately $20 \%$ of all survey dives were conducted by observers with 20 or 


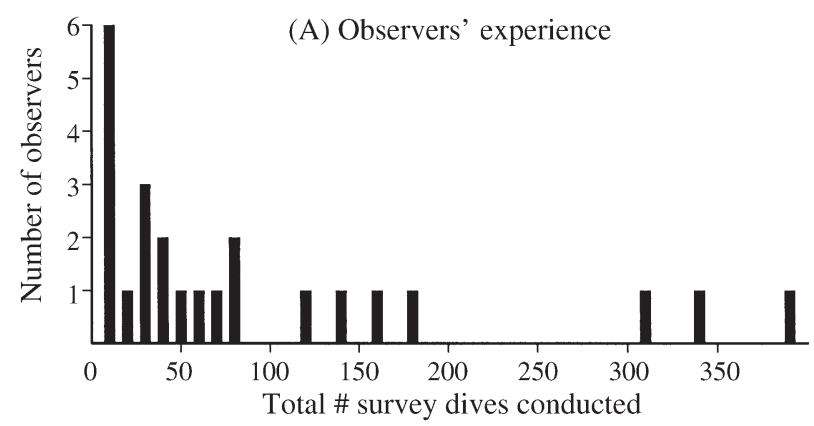

(B) Cumulative $\%$ of counts

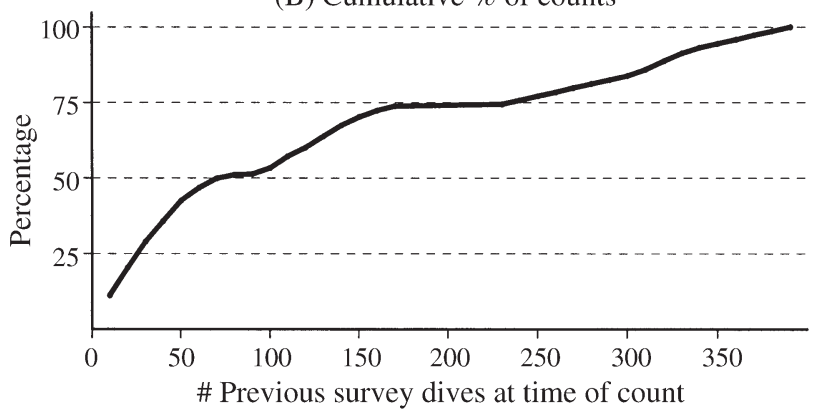

Fig. 1. Experience level of observers involved in survey program. Data are for all observers active in rounds 25 to 32. Experience is measured in terms of number of previous survey dives in this program. (A) Maximum experience level reached by all observers involved in the survey program in the period (February 2003 to May 2004) from which we took data. (B) Cumulative proportion of survey dives conducted by observers with increasing experience level

fewer previous survey dives at the time of the survey, $50 \%$ by people with 60 or fewer previous dives, and around $25 \%$ by people with 200 or more previous dives (Fig. 1B).

Observers were haphazardly assigned to survey teams, with the broad aim of maintaining approximately equivalent experience levels. In most cases, teams consisted of 2 core staff and 2 students, and 2 inexperienced observers were never assigned to the same survey pair. While all observers had been trained and had been through a quality-control program, there were and will continue to be large differences in experience among observers. Therefore, it was important for us to quantify the effect, if any, of observers' experience levels on fish-count data.

Data analysis. Few species were encountered frequently enough for us to be able to make meaningful comparisons at that level, and therefore data were aggregated into higher taxonomic groupings. Our assumption was that if experience level was an important factor, its importance would likely vary depending on the detectability and behavioral characteristics of target groups (Lincoln Smith 1989, Cheal \& Thompson 1997, Kulbicki 1998, Samoilys \& Carlos 2000), and so we wanted groups to be broadly similar in those respects, while still reflecting as much as possible the kinds of groupings that would commonly be used in analyses of monitoring data. Therefore, data were analyzed by family for Acanthuridae, Chaetodontidae, Cirrhitidae, Holocentridae, and Labridae and by genera for 2 groups of Pomacentridae (Chromis [mid-water Pomacentridae] and Stegastes \& Plectroglyphidodon [benthic Pomacentridae]), these being the 6 most abundant families recorded in fish counts. Zooplanktivorous acanthurids (Naso brevirostris, Naso hexacanthus, and Acanthurus thompsoni) were excluded on the basis that they were distinctly behaviorally different from other acanthurids. Furthermore, and in order to remove variability driven by occasional large numbers of recently recruited individuals, fishes $<5 \mathrm{~cm}$ were excluded from the data for all groups other than pomacentrids.

The core units of analysis were (1) mean number of fishes in each of those taxonomic groupings, or (2) mean species richness, i.e. number of species recorded per observer per survey dive (the mean of the 2 transects surveyed per observer per dive, either the shallow pair of transects 'AB', or the deeper pair of transects 'CD' at a single site). In order to reduce variability among observers' counts due to inherent differences in fish abundance or richness among the permanent transects surveyed or among the survey rounds, data were standardized by transect and round prior to analysis. Standardization was done by applying a 'round adjustment' and 'transect adjustment' to actual counts using the following formula:

$$
x_{i j}^{\prime}=x_{i j}+\left(\bar{x}-\bar{x}_{i}\right)+\left(\bar{x}-\bar{x}_{i}\right)
$$

where $x_{i j}$ is the actual count for Round $i$ (8 rounds were conducted between February 2003 and May 2004) and Transect $j$ (being 1 of the 92 transects surveyed: 4 permanent transects at each of 23 sites), $\bar{x}$ is the mean of counts from all transects and all rounds, $\bar{x}_{i}$ is the mean of counts from all transects in Round $i$, and $\bar{x}_{j}$ is the mean of counts from all rounds at Transect $j$.

Effects of observers' experience on bias and precision. In rounds between February 2003 and May 2004, a total of 736 dives were conducted by the 24 survey divers active in the program (8 rounds, 23 sites surveyed once per round, 4 divers per site survey: $8 \times 23 \times$ 4 = 736). All except one of the survey divers had little or no marine survey experience prior to beginning the training for our program, and we therefore quantified their experience at the time of each survey dive in terms of the number of previous survey dives they had conducted with us. The other survey diver was much more highly trained and experienced than other surveyors (>25 yr in marine science). We could not quantify his experience in a way which would be comparable with other survey divers, and so data from that 
observer were not used in analyses of trends relating to experience. Another 2 divers conducted 3 or fewer survey dives in the period from which we took data, and were therefore also excluded from analyses, on the basis that there was insufficient replication for meaningful quantification of their performance. All other observers had conducted 6 or more dives in the period.

For each of the remaining 21 observers, we calculated their average experience level as the mean number of previous surveys they had conducted. For example, if an observer had conducted 20 previous survey dives at the start of the period from which we took data, and then conducted a further 10 dives, their experience level would have increased from 20 to 30, and their mean experience level over that time would be 25 .

The potential for bias relating to observers' experience was assessed in terms of mean number of fish and number of species counted by observers, and the potential impact of experience on survey data precision, in terms of the COV of observers' counts. The impact of experience level on survey performance, quantified in these 2 ways, was analyzed by means of linear regressions with survey data (number of fish or species counted, or COV, per observer) as dependent variables and log-transformed experience level as the independent variable. Log-transformation seemed appropriate as observers' experience was highly right skewed-there were many individuals with limited experience and relatively few very experienced observers (Fig. 1)-and because we expected the impact, if any, of increasing experience to decline as observers became more practiced, i.e. the potential impact of increasing experience arising from going from 0 to 10 previous dives would likely be much greater than that arising from going from 100 to 110 previous dives.

\section{RESULTS}

\section{Effect of observers' experience on estimates of species richness}

Experienced observers tended to count more species per transect than inexperienced observers (Fig. 2A) (linear regression of richness on the logarithm of mean experience, $\mathrm{df}=20, \mathrm{r}^{2}=0.31, \mathrm{p}<0.01$ ). The mean richness estimate of the 5 survey divers with 10 or fewer dives was $14.9 \pm 0.7$ (SD) species per transect, and the mean richness estimate of the 7 survey divers with 100 or more previous dives was $17.2 \pm$ 0.4 species per transect. There was no indication that experience level affected the precision of richness estimates (Fig. 2B).

\section{Observers' experience and bias}

The impact of experience level on the number of fish counted differed among taxonomic groupings (Fig. 3): there were no significant differences relating to experience level in terms of the number of Chaetodontidae counted (regression $\mathrm{df}=20, \mathrm{r}^{2}=0.06, \mathrm{p}=0.30$ ), the number of Chromis counted (regression $\mathrm{df}=20, \mathrm{r}^{2}=$ 0.04, $\mathrm{p}=0.39$ ), or the number of Cirrhitidae counted (regression $\mathrm{df}=20, \mathrm{r}^{2}=0.12, \mathrm{p}=0.12$ ). However, there were significant differences for all other taxonomic groups. Experience level was positively associated with Labridae counts (regression $\mathrm{df}=20, \mathrm{r}^{2}=0.37, \mathrm{p}=$ 0.003), Acanthuridae counts ( $\mathrm{df}=20, \mathrm{r}^{2}=0.53, \mathrm{p}<$ 0.001), benthic Pomacentridae counts (Stegastes and Plectroglyphidodon: $\mathrm{df}=20, \mathrm{r}^{2}=0.35, \mathrm{p}=0.005$ ), and Holocentridae counts ( $\left.d f=20, r^{2}=0.40, p=0.002\right)$. The scale of the differences among different experience groups was substantial: the mean counts of the 5 divers

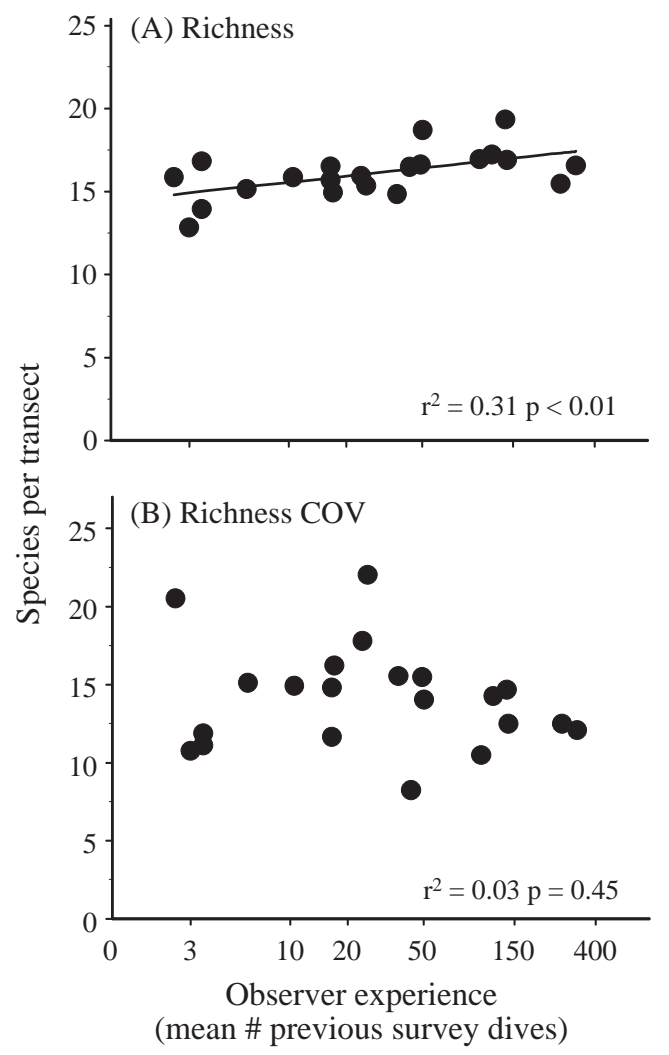

Fig. 2. Observers' experience level and (A) mean richness and (B) coefficient of variation (COV) of richness estimates, for all survey divers involved in the West Hawai'i Aquarium Project. Each data point represents a single observer. Observer experience is the mean level for that individual over the period from which we took data, measured in terms of mean number of previous dives, and is displayed on a $\log _{e}$ scale; $r^{2}$-values and $\mathrm{p}$-values were derived from linear regressions of mean richness, or COV, on log-transformed experience level. Solid trend line indicates a significant regression (at $\alpha=0.05$ ) 
with $<10$ previous dives were 66 to $71 \%$ of the mean counts of the 7 divers with $>100$ previous dives for Acanthuridae, Labridae, and benthic Pomacentridae, and $44 \%$ for Holocentridae.

\section{Observers' experience and precision}

There were no significant associations or even clear trends between COVs and experience level (Fig. 4) (linear regression of COVs on log-transformed experience level, $\mathrm{df}=20, \mathrm{r} \leq 0.14, \mathrm{p} \geq 0.10$ in all cases). However, there was some indication of high COVs among very inexperienced observers; those with a mean experience level of around 3 previous dives, particularly for the least abundant groups of fishes: Cirrhitidae, Holocentridae, and Stegastes/Plectroglyphidodon (Fig. 4). All those groups were generally recorded in rather low numbers, even for experi- enced observers; mean counts were around 2 per transect (Fig. 3), and high COVs for 1 or 2 novice observers in each of those taxonomic groupings principally reflect low counts by those observers rather than high absolute variance.

\section{DISCUSSION}

We found clear evidence of a relationship between the amount of observers' previous survey experience and the number of fish and number of species they counted per survey. Furthermore, the scale of difference in counts between the most experienced and the least experienced observers was substantial: the least experienced observers, those with $<10$ previous survey dives, counting around $15 \%$ fewer species, and $>30 \%$ fewer fishes in several taxa than observers with $>100$ previous survey dives. That was in spite of the fact that the program we took data from had multiple quality-control measures, including the requirements that personnel working on the survey program had (1) received training in species identification and survey methods, (2) followed an explicit protocol, and (3) only counted fishes within rather narrow transects (2 m wide), all of which would likely reduce survey error (Sale \& Sharp 1983, Thompson \& Mapstone 1997, Samoilys \& Carlos 2000). There may be scope for improving conformity of our observers by further, or better, training, or by modifying the survey methodology so that a narrower range of information is collected (Harding et al. 2000). Nevertheless, it seems reasonable to assume that observerexperience effects could be important in many multi-observer survey programs, particularly those involving the kind of comprehensive multi-species surveys that we carried out.

The impact of observers' experience appeared to be strongly related to the detectability of different taxonomic groups, as experience was not a factor in the number of (1) Chaetodontidae, (2) Chromis, or (3) Cirrhitidae counted, those being, respectively: (1) large, brightly colored and slow-swimming fishes; (2) conspicuous mid-water fishes; and (3) relatively immobile fishes, which typically rest on elevated portions of the benthos. In contrast, observers experience was an important factor in counts of Acanthuridae, Labridae, and benthic Pomacentridae (Stegastes \& Plectroglyphidodon), all groupings which were numerically dominated by smallish and fairly mobile individuals which were 

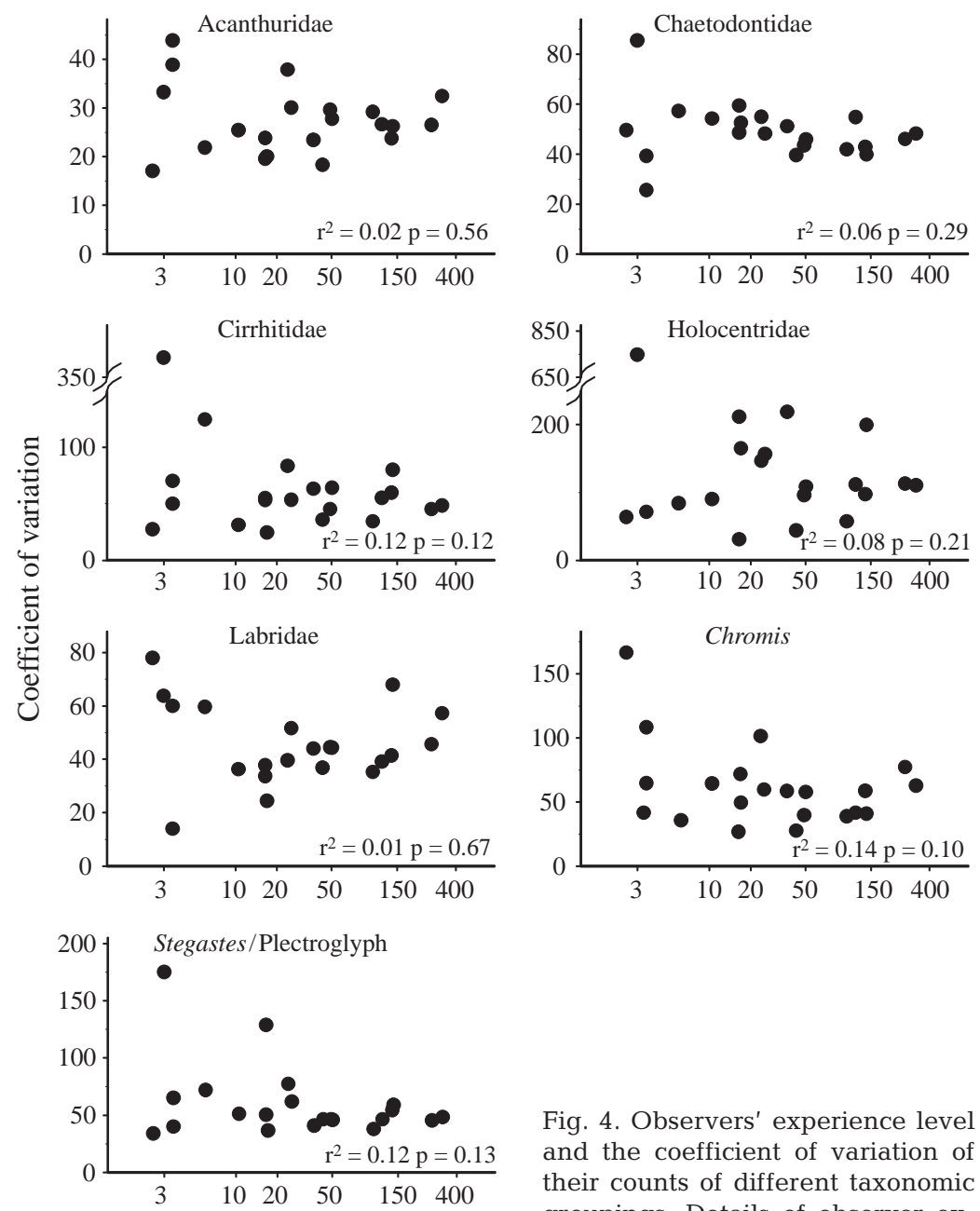

Observers' experience (mean \# previous survey dives)

Fig. 4. Observers' experience level and the coefficient of variation of their counts of different taxonomic groupings. Details of observer experience and taxonomic grouping as for Fig. 2 and Fig. 3, respectively and residuals are generally well balanced around lines of best fit throughout the experience range from which we have data), have the benefit of simplicity and consistency (the same model was applied to all data sets), and share the essential characteristics of any model we might reasonably apply, namely, that small to moderate increases in experience tend to have a great impact on observers' counts at the low end of the experience spectrum, but only rather marginal, if any, impact on the performance of experienced observers. Certainly, as experience levels increase, other sources of difference among individual observers (St John et al. 1990) will become much more important than relative experience.

Assuming that underwater visual surveys generally underestimate density (Sale \& Douglas 1981, Brock 1982, Sale \& Sharp 1983, Samoilys \& Carlos 2000), higher counts by more experienced observers would be consistent with those observers being more accurate. However, it is unwise to assume that underwater visual surveys accurately estimate actual population sizes (St John et al. 1990, Jennings \& Polunin 1995), and, in any case, for survey programs which aim to detect differences among sites or time periods, it is only necessary that surveys give good relative measures of density or diversity. Therefore, to remove experience bias, it would be sufficient for survey programs to broadly balance observers' experience level among surveys. Assuming our findings are more generally frequently to some extent hidden among coral heads and other structurally complex benthic features. The greatest impact of experience on counts was for the most cryptic group, Holocentridae. Such differences among taxa, corresponding with fairly simple behavioral or physical characteristics, indicate that some groups of fishes are simply harder to count than others and reinforce the notion that tailored surveys that focus on a narrower range of taxa are likely to generate better-quality data (Thresher \& Gunn 1986, Lincoln Smith 1989, Samoilys \& Carlos 2000).

As with all such models, the log-linear fits we applied are simplifications of the real relationships between observers' experience and performance. In particular, it seems likely that there will be some point at which greater experience would not lead to any further change in performance and, therefore, that counts may actually tend towards an asymptote as experience increases. However, the simple log-linear models we applied fit our data well $\left(\mathrm{r}^{2}\right.$-values are relatively high applicable, the greatest scope for observer-experience bias will be found in programs that either (1) employ novice or inexperienced observers for at least some surveys or periods, or (2) employ observers with very widely differing levels of experience. Small changes in experience level among surveys would likely have smallish effects on resulting data, but experience bias could clearly be a problem for a program which begins with largely inexperienced staff who then gain experience as the program matures, particularly if there is some element of before versus after comparison; for example, in assessing the effects of creation of a marine reserve. The scale of differences we found between counts by novice and highly experienced observers was certainly comparable with what would be considered ecologically meaningful if they represented real differences among sites or time periods: the most experienced observers counting somewhere between 40 and $130 \%$ more fishes than the least experienced observers for some taxa. 
Other than for the analyses presented here, our survey data are always pooled by transect ( 2 observers transect ${ }^{-1}$ site $^{-1}$ ) and grouped by some combination of site ( 4 transects site ${ }^{-1}$ ), year (5 to 6 rounds $\mathrm{yr}^{-1} \mathrm{site}^{-1}$ ), or site status (unprotected, partially protected, fully protected) prior to analysis. Furthermore, in order to minimize scope for observer bias, survey sites were generally surveyed and analyzed in groups of 3, consisting of 1 protected, 1 partially protected, and 1 fully protected site, which were surveyed on the same day by the same dive teams. It seems likely therefore that any impact of observer-experience bias on our survey data would be negligible in comparison to the approximately $50 \%$ or greater effect sizes which we would expect to be around the lower limit of what would normally be statistically detectable (De Martini et al. 1996, Samoilys \& Carlos 2000).

In summary, observer experience level is a potentially important source of error in underwater visual surveys, particularly for harder to count taxa. While experience level is certainly not the only factor causing differences among observers (St John et al. 1990, Thompson \& Mapstone 1997), it is relatively easy to identify situations in which it might be a source of bias. Resource managers and scientists in charge of survey programs should seek to avoid gross differences in experience level among teams of observers involved in surveys at different sites or times.

Acknowledgements. The West Hawai'i Aquarium Project (WHAP), the source of the data presented here, was funded by grants from the Hawai'i Coral Reef Initiative Research Program, and by core funds from the State of Hawai'i's Division of Aquatic Resources. Brent Carman, Steve Cotton, Kara Osada, Sara McCutcheon, Josh Ballauer, Marc Hughes, Jeff Muir, Darla White, Lisa Wedding, Chad Wiggins, Chelsea Settlemier, Delisse Ortiz, Jeff Eble, Jan Direking, Joe Laughlin, Jim Gunderson, Julien Stevens, Kosta Stamoulis, Linda Preskitt, Paula Ayotte, Scarlett Mraz, and Zach Caldwell helped to gather data used in this paper. Jan Marsh, Laura Livnat, John Coney, and Dave Pence provided technical or administrative support.

\section{LITERATURE CITED}

Brock RE (1982) A critique of the visual census method for assessing coral-reef fish populations. Bull Mar Sci 32: 269-276

Charton JAG, Williams ID, Ruzafa AP, Milazzo M and 5 others (2000) Evaluating the ecological effects of Mediterranean marine protected areas: habitat, scale and the natural variability of ecosystems. Environ Conserv 27: $159-178$

Cheal AJ, Thompson AA (1997) Comparing visual counts of

Editorial responsibility: Charles Birkeland (Contributing Editor), Honolulu, Hawaii, USA coral reef fish: implications of transect width and species selection. Mar Ecol Prog Ser 158:241-248

De Girolamo M, Mazzoldi C (2001) The application of visual census on Mediterranean rocky habitats. Mar Environ Res 51:1-16

De Martini EE, Parrish FA, Parrish JD (1996) Interdecadal change in reef fish populations at French Frigate Shoals and Midway Atoll, northwestern Hawaiian Islands: statistical power in retrospect. Bull Mar Sci 58:804-825

Hallacher LE, Tissot BN (1999) QUEST: Quantitative Underwater Ecological Survey Techniques. In: Maragos JE, Grober-Dunsmore R (eds) Hawai'i coral reef monitoring workshop. East-West Center and the Hawaii Department of Land and Natural Resources, Honolulu, p 147-158

Harding S, Lowery C, Oakley S (2000) Comparison between complex and simple reef survey techniques using volunteers: Is the effort justified? In: Moosa MK, Soemodihardjo S, Soegiarto A, Romimohtarto K, Nontji A, Soekarno, Suharsono (eds) Proceedings of the 9th international coral reef symposium. International Coral Reef Society, Bali, p 883-889

Jennings S, Polunin NVC (1995) Biased underwater visual census biomass estimates for target-species in tropical reef fisheries. J Fish Biol 47:733-736

Kulbicki M (1998) How the acquired behaviour of commercial reef fishes may influence the results obtained from visual censuses. J Exp Mar Biol Ecol 222:11-30

Kulbicki M, Sarramegna S (1999) Comparison of density estimates derived from strip transect and distance sampling for underwater visual censuses: a case study of Chaetodontidae and Pomacanthidae. Aquat Living Resour 12: 315-325

Lincoln Smith MP (1988) Effects of observer swimming speed on sample counts of temperate rocky reef fish assemblages. Mar Ecol Prog Ser 43:223-231

Lincoln Smith MP (1989) Improving multispecies rocky reef fish censuses by counting different groups of species using different procedures. Environ Biol Fishes 26:29-37

Sale PF, Douglas WA (1981) Precision and accuracy of visual census technique for fish assemblages on coral patch reefs. Environ Biol Fishes 6:333-339

Sale PF, Sharp BJ (1983) Correction for bias in visual transect censuses of coral reef fishes. Coral Reefs 2:37-42

Samoilys MA, Carlos G (2000) Determining methods of underwater visual census for estimating the abundance of coral reef fishes. Environ Biol Fishes 57:289-304

St John J, Russ GR, Gladstone W (1990) Accuracy and bias of visual estimates of numbers, size structure and biomass of a coral-reef fish. Mar Ecol Prog Ser 64:253-262

Stewart BD, Beukers JS (2000) Baited technique improves censuses of cryptic fish in complex habitats. Mar Ecol Prog Ser 197:259-272

Thompson AA, Mapstone BD (1997) Observer effects and training in underwater visual surveys of reef fishes. Mar Ecol Prog Ser 154:53-63

Thresher RE, Gunn JS (1986) Comparative-analysis of visual census techniques for highly mobile, reef-associated piscivores (Carangidae). Environ Biol Fishes 17:93-116

Tissot BN, Walsh WJ, Hallacher LE (2004) Evaluating effectiveness of a marine protected area network in West Hawai'i to increase productivity of an aquarium fishery. Pac Sci 58:175-188

Submitted: January 26, 2005; Accepted: August 26, 2005

Proofs received from author(s): February 15, 2006 